\title{
Desenvolvimento testicular, espermatogênese e concentrações hormonais em touros Angus
}

\author{
Gyselle Viana Aguiar ${ }^{1}$, Airton Alencar Araújo ${ }^{2}$, Arlindo de Alencar Araripe Moura ${ }^{2}$ \\ ${ }^{1}$ Programa de Pós-graduação em Zootecnia- UFC. \\ 2 Departamento de Zootecnia-UFC.
}

RESUMO - Este estudo foi realizado com a finalidade de avaliar a evolução das secreções hormonais e do epitélio seminífero em touros da raça Angus de 10 a 38 semanas de idade. Foram castrados 1 a 5 animais em intervalos de quatro semanas (total de 25 touros) para coleta de amostras do parênquima testicular e do plasma sanguíneo. As variáveis relacionadas ao crescimento testicular, aos aspectos quantitativos da espermatogênese e aos níveis hormonais foram transformadas em logaritmo e avaliadas por meio de análise de variância. O diâmetro dos testículos e túbulos seminíferos e o peso testicular apresentaram variações mais acentuadas após 26 semanas de idade. A porcentagem do parênquima testicular ocupado pelos túbulos seminíferos aumentou de 49,3 para 75,2\% durante o experimento. A maioria dos túbulos (>90\%) apresentou-se com células de Sertoli somente entre 10 e 14 semanas, mas na $18^{\mathrm{a}}(13,8 \pm 1,7 \%)$ e $22^{\mathrm{a}}$ semanas $(19 \pm 1 \%)$, o número de túbulos com gonócitos e espermatogônias aumentou em relação às semanas iniciais. Espermatogônias intermediárias e B predominaram na $26^{\mathrm{a}}$ semana $(24,5 \pm 8,2 \%)$ e a porcentagem de túbulos com espermatócitos foi mais elevada na $30^{\mathrm{a}}$ semana $(42,3 \pm 9,9 \%)$. Espermátides arredondadas foram detectadas partir da $26^{\mathrm{a}}$ semana e, na $38^{\mathrm{a}}$ semana, $62,3 \pm, 5 \%$ dos túbulos seminíferos continham espermátides alongadas ou maduras. As variações mais acentuadas no crescimento testicular e, principalmente, no peso testicular após as 26 semanas coincidiram com o estabelecimento da meiose, com as alterações morfológicas do núcleo e nucléolo das células de Sertoli (indicativos do processo de diferenciação das mesmas), com os níveis reduzidos de androstenediona e os incrementos significativos de testosterona e estradiol $17 \beta$. As associações entre o crescimento testicular e os níveis de FSH e LH na circulação periférica foram menos evidentes.

Palavras-chave: estradiol, Sertoli, testículos, testosterona

\section{Testicular development, spermatogenesis and hormonal concentrations in Angus bulls}

\begin{abstract}
This study aimed to evaluate changes in hormone secretion and in seminiferous epithelium of Angus bulls between 10 and 38 weeks of age. Samples of testicular parenchyma and blood were collected from 25 animals castrated in 4 week intervals. Traits associated to testicular development and quantitative aspects of spermatogenesis and hormonal concentrations were transformed by logarithm before analyses of variance. Changes in testis and seminiferous tubule diameter and testis weight were more pronounced after 26 weeks of age. The percentage of testicular parenchyma occupied by seminiferous tubules increased from 49.3 to $75.2 \%$ from 10 to 38 weeks. Most tubules $(>90 \%)$ had only Sertoli cells at 10 and 14 weeks, but the number of tubules with gonocytes and A spermatogonia increased at $18(13.8 \pm 1.7 \%)$ and 22 weeks $(19 \pm \%)$. Tubules with B and intermediate spermatogonia became predominant at 26 weeks $(24.5 \pm 8.2 \%)$ and those with spermatocytes as the most advanced germ cell type were more evident at 30 weeks $(42.3 \pm 9.9 \%)$. Round spermatids were detected at 26 weeks and at 38 weeks of age, $62.3 \pm 1.5 \%$ of all tubules had either elongate or mature spermatids. Variations in testis growth (specially testis weight) after 26 weeks were coincident with the establishment of meiosis in the seminiferous tubules, morphological alterations in nucleus and nucleolus of the Sertoli cells (indicators of Sertoli cell differentiation), lower levels of androstenedione and significant increases in testosterone and estradiol 17ß. Associations between testis development and concentrations of FSH and LH were less evident.
\end{abstract}

Key Words: estradiol, Sertoli, testis, testosterone

\section{Introdução}

A espermatogênese é um processo cíclico no qual os gonócitos, primeiras células germinativas a habitarem os túbulos seminíferos, multiplicam-se e diferenciam-se em espermatogônias. A última geração destas células, formada pelas espermatogônias B, sofre meiose, formando os espermatócitos primários e as espermátides arredondadas, 
que se diferenciam em espermatozóides (Griffin, 1988; Curtis \& Amann, 1981; Courot et al., 1970; Russell \& França, 1994). O desenvolvimento da espermatogênese depende do suporte funcional das células de Sertoli (Martin-du Pan \& Campana, 1993), dos níveis adequados de esteróides, goandotrofinas e de fatores de crescimento (Sharpe, 1994).

O processo de multiplicação, meiose e diferenciação das células germinativas em estádios mais avançados de desenvolvimento está sincronizado com as mudanças morfológicas e a expressão gênica nas células de Sertoli e Leydig (Anway et al., 2003; Walker, 2003) e as secreções hormonais. As gonadotrofinas (LH e FSH) controlam a proliferação e a diferenciação das células de Sertoli e Leydig desde a fase pós-natal, de modo que os esteróides e fatores de crescimento secretados por estas células têm ação direta ou indireta sobre o desenvolvimento das células germinativas. Especificamente na espécie bovina, o início da puberdade está associado à habilidade das células de Leydig em responder ao estímulo do LH (Boockfor et al., 1983), produzindo crescentes quantidades de testosterona, que, por sua vez, controla a diferenciação das células de Sertoli e, conseqüentemente, várias de suas funções (Griffin, 1988). Estes eventos regulam a espermatogênese de forma concatenada, de modo que alterações na função das células de Sertoli alteram o crescimento das céluas germinativas (Sharpe, 1994; Sharpe et al., 2003). As interrupções no processo espermatogênico também inferferem nas células de Sertoli (Moura \& Erickson, 2001) causando, em última instância, modificações no padrão normal de desenvolvimento e na capacidade reprodutiva dos animais. Neste caso, o conhecimento da espermatogênese e fisiologia testicular é fundamental para a identificação de causas potenciais de infertilidade e subfertilidade e a compreensão dos processos que definem a capacidade de produção espermática. Importantes informações têm sido obtidas nos últimos anos sobre as modificações fisiológicas das células de Sertoli e germinativas que ocorrem na fase de prépuberdade (Sharpe et al., 2003; Mackay, 2000), mas estes eventos e as interações entre os hormônios da circulação periférica e o crescimento testicular não estão completamente estabelecidos em touros de corte. Portanto, realizou-se este trabalho com o objetivo de estudar a evolução das secreções hormonais, da espermatogênese e das células de Sertoli em touros da raça Angus durante as fases iniciais de desenvolvimento do sistema reprodutivo.

\section{Material e Métodos}

Vinte e cinco touros da raça Angus foram divididos em oito grupos (1 a 5 indivíduos/grupo) e castrados cirurgica- mente entre 10 e 38 semanas de idade a intervalos de quatro semanas. Depois de separados da túnica vaginal e do epidídimo, os testículos foram pesados e medidos (diâmetro do testículo esquerdo). Dois segmentos de aproximadamente $4 \mathrm{~mm}$ de espessura foram coletados de cada pólo do testículo esquerdo, fixados por 24 horas em líquido de Bouin, lavados em água e etanol (70\%) e mantidos em etanol $(70 \%)$. Posteriormente, as amostras foram colocadas em parafina, seccionadas com $5 \mu \mathrm{m}$ de espessura e coradas com hematoxilina e eosina (Moura \& Erickson, 1997). Nos períodos das castrações, os animais também foram pesados e três amostras de sangue foram coletadas de cada touro em intervalos de 1 hora, utilizando-se tubos com EDTA. Após centrifugação, o plasma foi separado em alíquotas e mantido a $-80^{\circ} \mathrm{C}$ para posterior dosagem das concentrações hormonais por meio de radioimunoensaios. Utilizou-se a média das concentrações entre as três coletas basais em cada idade para análise estatística. Os animais utilizados neste estudo faziam parte dos rebanhos de corte da Universidade do Tennessee, região sul dos Estados Unidos. Em geral, o manejo destes animais consistiu de sua manutenção com as matrizes em regime de pastagem até os 8 meses de idade (desmame) e em confinamento nas idades subseqüentes, com suplementação à base de feno, silagem de milho e concentrado.

As proporções do volume do parênquima testicular ocupado por túbulos seminíferos e interstício foram determinadas por meio da contagem de 600 pontos aleatórios/ lâmina (aumento de $400 \mathrm{x}$ ) utilizando-se um ponto no retículo da ocular, conforme descrito anteriormente (Moura \& Erickson, 1997). O estádio de desenvolvimento do epitélio seminífero dos touros foi determinado em 400 secções transversais de túbulos/animal $(400 \mathrm{x})$. Cada secção foi classificada de acordo com o estádio de desenvolvimento mais avançado das células germinativas: 1) túbulos sem células germinativas; 2) túbulos com espermatogônias A; 3) túbulos com espermatogônias intermediárias ou B; 4) túbulos com espermatócitos em paquíteno, 5) túbulos com espermátides arredondadas e 6) túbulos com espermátides alongadas ou maduras (Moura \& Erickson, 1999).

Em dez secções transversais de túbulos avaliadas aleatoriamente nas amostras de testículo de cada animal, determinaram-se ainda o número de células de Sertoli e germinativas (espermatogônias A; espermatogônias intermediárias ou B; espermatócitos, espermátides arredondadas) e os diâmetros dos túbulos. Somente células com núcleo e nucléolo intactos foram consideradas na contagem (Moura \& Erickson, 1997; Souza, 2003; Souza et al., 2003).

As concentrações de FSH foram determinadas em amostras de $200 \mu \mathrm{L}$ de plasma por meio de radioimunoensaio 
(Bolt \& Rollins, 1983). O primeiro anticorpo (USDA-50122), o FSH purificado para reação com iodo radioativo e a curva de referência (USDA-bFSH-I-2) foram cedidos pelo Dr. D. J. Bolt (USDA, Beltsville, MD). O nível de detecção deste ensaio foi $0,25 \mathrm{ng} / \mathrm{mL}$ e o coeficiente de variação intra-ensaio, $10 \%$. As concentrações de LH foram estimadas em $100 \mu \mathrm{L}$ de soro, conforme método desenvolvido por Niswwender et al. (1969) e posteriormente modificado por Bolt (1981). O primeiro anticorpo (LH antiovino no. 15) foi adquirido do Dr. G. Niswender (CSU, Fort Collins, CO) e o hormônio purificado para reação com iodo radioativo e a curva de referência foram cedidos pelo Dr. L. E. Reichert (Rochester Medical School, Albany, NY). O nível de detecção foi de $31,3 \mathrm{pg} / \mathrm{mL}$ e o coeficiente de variação intra-ensaio, $6.5 \%$. No caso dos esteróides, as amostras de plasma foram primeiramente dissolvidas e extraídas em 1,5 mL de benzeno. As concentrações de testosterona e androstenediona $\left(\mathrm{D}_{4} \mathrm{~A}\right)$ foram estimadas conforme método descrito por Cox et al. (1987). $\mathrm{O}$ anticorpo para $\mathrm{D}_{4} \mathrm{~A}$ (X - $322 \mathrm{Rao}$ ) foi adquirido do Dr. P. N. Rao (Southwest Foundation for Biomedical Research, San Antônio, TX) e o anticorpo para testosterona foi cedido pelo Dr. G. Niswender. Os níveis de detecção foram $10 \mathrm{pg} / \mathrm{mL}$ e 2,5 pg/mL para os ensaios de testosterona e $\mathrm{D}_{4} \mathrm{~A}$, respectivamente. Os coeficientes de variação intra-ensaio foram 10 e $8 \%$, respectivamente. As concentrações de estradiol foram quantificadas de acordo com o método desenvolvido por Cox et al. (1987), posteriormente modificado para a espécie bovina por meio do aumento da diluição do anticorpo de 1:800.000 para 1:1.500.000 e da diminuição da quantidade de soro extraído e utilizado no ensaio (Britt, comunicação pessoal, Knoxville, TN, USA). O anticorpo foi cedido por Dr. N. Manson (Lilly Research Laboratories, Indianapolis, IN). O nível de detecção do ensaio foi de $0,15 \mathrm{pg} / \mathrm{mL}$ e o coeficiente de variação intra-ensaio, 7\%. Os radioimunoensaios foram validados adicionando-se quantidades de hormônios a amostras de plasma previamente caracterizadas, estimando-se as concentrações nestas amostras conforme procedimento supracitado (Moura \& Erickson, 1997).

As variáveis relacionadas ao crescimento testicular, aos aspectos quantitativos da espermatogênse e às concentrações hormonais foram transformadas em logaritmo para avaliação, por meio de análise de variância, das diferenças relacionadas às idades (SAS, 2003). Como na $14^{\mathrm{a}}$ semana de idade houve coleta de amostras de um único animal, os valores referentes a esta idade não foram incluídos nas comparações.

\section{Resultados e Discussão}

Todas as medidas associadas ao crescimento das gônadas e dos túbulos seminíferos dos touros apresentaram variações significativas entre a $10^{\mathrm{a}}$ e a $38^{\mathrm{a}}$ semana (Figura 1), todavia, o padrão de mudança destas variáveis foi diferente neste período. O peso testicular aumentou dez vezes, enquanto, no mesmo período, o peso vivo dos animais variou apenas 1,8 vezes (de 149,5 a 272,1 kg). As medidas de diâmetro testicular e diâmetro dos túbulos seminíferos cresceram 2,2 e 2,4 vezes, respectivamente, e a menor variação ( 1,5 vezes) foi observada para a porcentagem do parênquima testicular ocupado pelos túbulos seminíferos, de $49,3 \%$ na $10^{\mathrm{a}}$ semana a $75,2 \%$ na $38^{\mathrm{a}}$ semana de idade. Distintas fases de crescimento do peso testicular (Figura 1) também foram observadas, de modo que esta característica aumentou 2,7 vezes entre a $10^{\mathrm{a}}$ e a $22^{\mathrm{a}}$ semana e 3,7 vezes entre a $22^{\mathrm{a}}$ e a $38^{\mathrm{a}}$ semana. O crescimento das outras variáveis (Figura 1) apresentou evolução mais gradual durante todo o período de 10 a 38 semanas de idade. Houve redução temporária na média do peso testicular e no peso vivo dos animais durante a $26^{\mathrm{a}}$ semana, mas o padrão normal de crescimento foi retomado nas semanas seguintes. Este evento pode ter sido causado por alterações temporárias no manejo das matrizes e/ou dos próprios tourinhos. O modelo de crescimento do diâmetro testicular apresentado neste estudo é semelhante ao descrito por Chandolia et al. (1997), Moura \& Erickson (1997) e Aravindakshan et al. (2000). Em estudos conduzidos com touros holandeses e Hereford, respectivamente, Curtis \& Amann (1981) e Evans et al. (1996) obtiveram resultados similares em relação ao aumento do peso testicular, mais lento até as 25 semanas de idade, porém, com crescimento mais acentuado até a $32^{\mathrm{a}}$ e a $40^{\mathrm{a}}$ semanas de idade. No caso dos resultados apresentados por Evans et al. (1996), houve ainda pequena tendência a um decréscimo do diâmetro dos túbulos seminíferos entre a $20^{\mathrm{a}}$ e $25^{\mathrm{a}}$ semanas de idade, como ocorreu também neste estudo na $26^{\mathrm{a}}$ semana.

Sugere-se que a expansão do diâmetro dos túbulos seminíferos verificada neste estudo, principalmente a partir da $26^{\mathrm{a}}$ semana de idade, deveu-se prioritariamente à maciça proliferação das células germinativas e à diferenciação das células de Sertoli, conforme demonstrado nas Figuras 5 a 6 e com base nos estudos realizados por Sinowatz \& Amselgruber (1986) e Curtis \& Amann (1981). O aumento do diâmetro dos túbulos seminíferos com o passar das semanas reflete diretamente a proporção do volume do parênquima testicular ocupado por esses túbulos. A multiplicação das células de Sertoli também pode ter contri- 

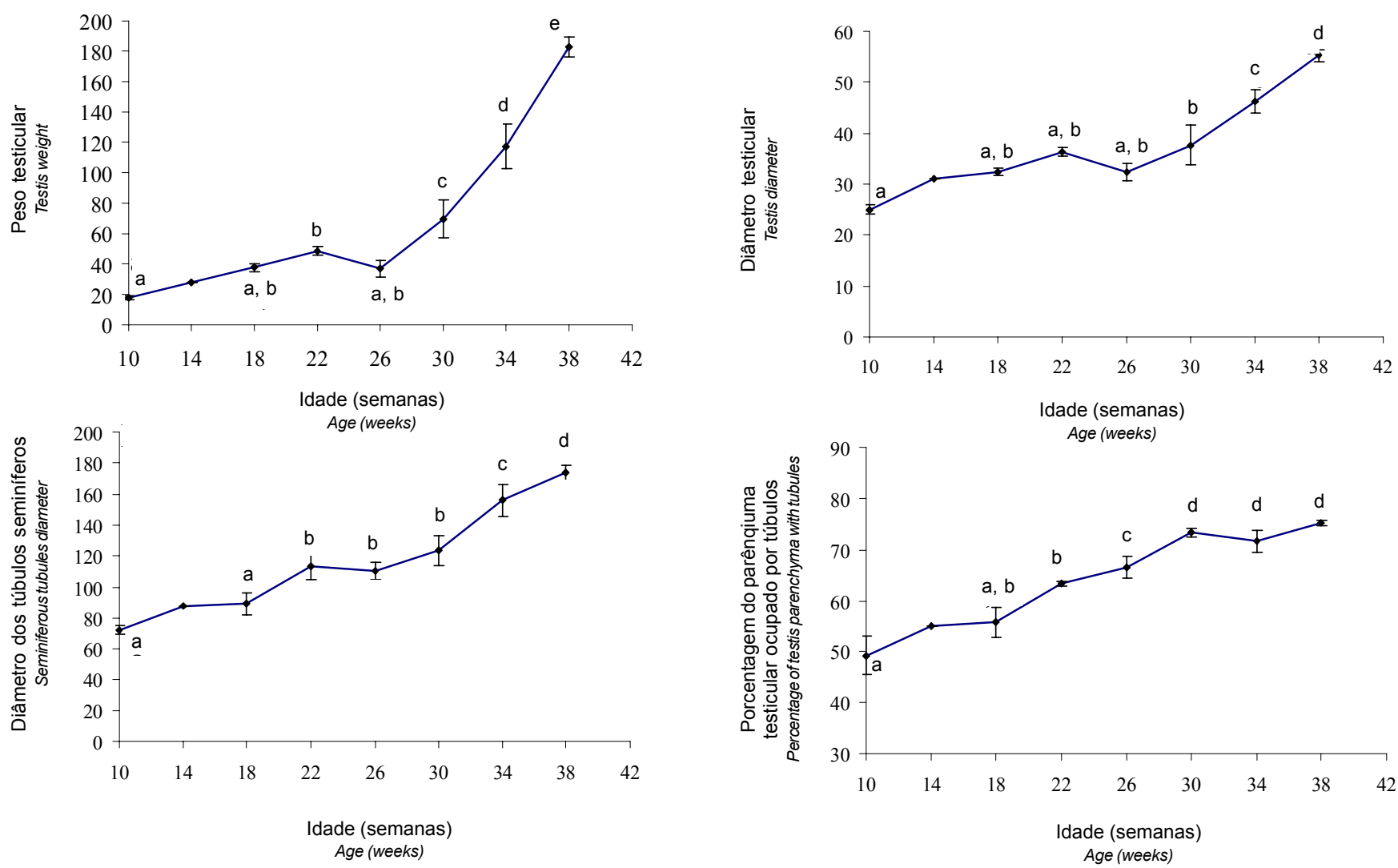

Figura 1 - Variáveis associadas ao desenvolvimento testicular de touros Angus (média \pm erro-padrão). Valores seguidos de letras idênticas não diferem $(\mathrm{P}>0,05)$. $\mathrm{Na} 14^{\mathrm{a}}$ semana, as amostras foram coletadas de apenas um touro e, portanto, não há o respectivo erro-padrão da média.

Figure 1 - Variables associated with the testicular development of Angus bulls (mean \pm standard error). Values followed by identical letters are not statistically significant $(P>0.05)$. At 14 weeks, samples were collected from only one bull and, therefore, no standard error of mean is shown.

buído para a expansão do diâmetro tubular e as medidas testiculares, mas este efeito certamente foi muito limitado, pois, na espécie bovina, as células de Sertoli tornam-se amitóticas até a $20^{\mathrm{a}}$ semana de idade (Sinowatz \& Amselgruber, 1986).

As análises dos cortes histológicos do parênquima testicular são importantes, pois indicam como o processo espermatogênico associa-se ao crescimento das gônadas. A maioria das secções transversais dos túbulos seminíferos apresentou somente células de Sertoli no início do desenvolvimento testicular (Tabela 1 ), de modo que, entre a $10^{\text {a }}$ e a $14^{\mathrm{a}}$ semana, não houve diferença na proporção de túbulos com células germinativas $(8,3 \pm 1,3$ vs $7,3 \%$, respectivamente). No entanto, a porcentagem de túbulos com gonócitos e espermatogônias A na $18^{\mathrm{a}}(13,8 \pm 1,7)$ e $22^{\mathrm{a}}$ semanas (19 \pm 1 ) aumentou significativamente em relação às semanas iniciais e, a partir destas idades, a proporção de túbulos com espermatogônias A como o tipo celular em estágio mais desenvolvido passou a decrescer (Tabela 1). Com base em estudos sobre a espermatogênese em touros holandeses (Amann, 1970; Curtis \& Amann, 1981), sugere-se que esta redução deveu-se à continuidade da proliferação e à diferenciação deste tipo celular em espermatogônias intermediárias e B, sucessivamente. De fato, estas duas classes de espermatogônias tornaram-se predominantes no lúmen dos túbulos na $26^{\mathrm{a}}$ semana $(24,5 \pm 8,2 \%)$, mas reduziram da $30^{\mathrm{a}}(7,7 \pm 5 \%)$ à $38^{\mathrm{a}}$ semana $(0,8 \pm 0,5 \%)$. A porcentagem de túbulos com células meióticas (espermatócitos) aumentou a partir da $22^{\mathrm{a}} \operatorname{semana}(7,1 \pm 2,9 \%)$, porém, somente nas semanas $26(34,8 \pm 14,7 \%)$ e $30(42,3 \pm$ $9,9 \%$ ) houve predominância deste tipo celular. A partir da $26^{\mathrm{a}}$ e $30^{\mathrm{a}}$ semanas, detectou-se a presença de espermátides arredondadas $(2,5 \pm 1,4 \%)$ e espermátides alongadas e maduras (12 $\pm 12 \%)$, com predominância destes tipos celulares nos túbulos seminíferos dos touros com 34 e 38 semanas de idade $(27,5 \pm 4,3$ e $62,3 \pm 1,5$, respectivamente; Tabela 1$)$. Quando relacionados às informações apresentadas na Figura 1, estes resultados evidenciam que a fase de crescimento mais lento das medidas testiculares (até 22-26 semanas de idade) ocorreu durante o processo de multiplicação 
e diferenciação das espermatogônias e que as variações mais acentuadas no diâmetro das gônadas e dos túbulos seminíferos e, principalmente, no peso testcular, coincidiram com o estabelecimento da meiose. Cada espermatogônia B tem capacidade potencial de gerar quatro espermátides arredondadas (Amann, 1970; Courot et al., 1970) e esta magnitude da divisão meiótica é responsável pela rápida substituição de parte do fluido tubular por células germinativas a partir da $26^{\mathrm{a}}$ semana de idade nos touros.

Nos períodos entre as semanas 18 e 22 e novamente entre as semanas 34 e 38 , houve decréscimo na população das células de Sertoli nas secções transversais dos túbulos seminíferos (Tabela 2). Este resultado é semelhante ao encontrado por Curtis \& Amann (1981), que relataram o mesmo decréscimo a partir da $20^{\mathrm{a}}$ semana de idade em touros holandeses. Porém, as células de Sertoli proliferam somente até a $20^{\mathrm{a}}$ semana de idade em bovinos e é pouco provável que tenha havido apoptose ou degeneração após esta idade, pois estas células são extremamente resistentes a lesões capazes de afetar outros tipos celulares nos túbulos seminíferos (Castro et al., 1997). Dessa forma, a aparente redução no número de células de Sertoli parece ter sido ocasionada pela intensa proliferação das células germinativas e pelo aumento do comprimento e diâmetro tubular, o que influencia o número proporcional das células de Sertoli por secção transversal de túbulo seminífero. A presença de maior número de células germinativas nos túbulos pode também se sobrepor às células de Sertoli e, desta forma, dificultar a visualização do núcleo e nucléolo quando da contagem com microscópio óptico.

As populações de espermatogônias A, Intermediárias e B por secção transversal dos túbulos permaneceram estabilizadas após a $22^{\mathrm{a}}$ e a $26^{\mathrm{a}}$ semana, no entanto, este mesmo período foi caracterizado por aumentos constantes na população de espermatócitos e principalmente espermátides arredondadas (Tabela 2). A relação do número de espermátides arredondadas com o de células de Sertoli aumentou consideravelmente nos túbulos seminíferos no período de 26 a 30 semanas até a $38^{\mathrm{a}}$ semanas, o que reflete a dinâmica da capacidade de suporte das células de Sertoli. Nesta idade final do experimento (38 semanas), foi estimada uma média de 1,6 espermátides/célula de Sertoli, mas este valor é transitório e tende a aumentar durante o desenvolvimento das gônadas. De fato, em estudos conduzidos com touros aos 12 meses de idade ( 52 semanas), uma média de 6,3 espermátides arredondadas por célula de Sertoli foi identificada em secções transversais de túbulos seminíferos (Moura \& Erickson, 1997). Considerando que as células de Sertoli não sofrem mitose após as 20 semanas de idade na espécie bovina (Sinowatz \& Amselgruber, 1986), o aumento na proporção com as espermátides após esta idade é resultado do estabelecimento da meiose e da ampliação do pool de espermatogônias nos túbulos seminíferos (Moura \& Erickson, 1997; Mackay, 2000; Wrobel, 2000; Walker, 2003). Portanto, a relação espermátide/célula de Sertoli é importante, pois reflete a capacidade de suporte das células de Sertoli e, em última instância, o potencial de produção

Tabela 1 - Desenvolvimento do epitélio seminífero de touros Angus, em função dos estádios mais avançados das células germinativas Table 1 - Development of the seminiferous epithelium of Angus bulls as related to the most advanced germ cell type

Idade (semanas)
Age (weeks)

\section{Porcentagem de secções transversais de túbulos seminíferos com células germinativas em estádio de desenvolvimento mais avançado (média \pm erro-padrão) \\ Percentage of cross sections of seminiferous tubules with the most developed germ cell type (mean \pm standard error)}

\begin{tabular}{cccc}
$\begin{array}{c}\text { Espermatogônias } \\
\text { ntermediárias ou B } \\
\begin{array}{c}\text { Intermediate or B } \\
\text { spermatogonia }\end{array}\end{array}$ & $\begin{array}{c}\text { Espermatócitos } \\
\text { Spermatocytes }\end{array}$ & $\begin{array}{c}\text { Espermátides } \\
\text { arredondadas } \\
\text { Round spermatids }\end{array}$ & $\begin{array}{c}\text { Espermátides } \\
\text { alongadas ou maduras } \\
\text { Elongate or mature } \\
\text { spermatids }\end{array}$ \\
\hline 0 & 0 & 0 & 0 \\
2,3 & 0 & 0 & 0 \\
$2,3 \pm 0,2^{\mathrm{a}}$ & $0,1 \pm 0,1^{\mathrm{a}}$ & 0 & 0 \\
$3,5 \pm 0,7^{\mathrm{a}}$ & $7,1 \pm 2,9^{\mathrm{b}}$ & 0 & 0 \\
$24,5 \pm 8,2^{\mathrm{b}}$ & $34,8 \pm 14,7^{\mathrm{c}}$ & $2,5 \pm 1,4^{\mathrm{a}}$ & 0 \\
$7,7 \pm 5^{\mathrm{c}}$ & $42,3 \pm 9,9^{\mathrm{c}}$ & $11,3 \pm 4,3^{\mathrm{b}}$ & $12 \pm 12^{\mathrm{a}}$ \\
$3,9 \pm 3,5^{\mathrm{a}}$ & $17,7 \pm 12,5^{\mathrm{d}}$ & $26,4 \pm 2,3^{\mathrm{c}}$ & $44 \pm 21,4^{\mathrm{b}}$ \\
$0,8 \pm 0,5^{\mathrm{d}}$ & $4,8 \pm 1,6^{\mathrm{b}}$ & $27,5 \pm 4,3^{\mathrm{c}}$ & $62,3 \pm 11,5^{\mathrm{b}}$
\end{tabular}

* Valores entre parênteses representam o número de touros castrados em cada idade. Na $14^{a}$ semanas, as amostras foram coletadas de apenas um touro e, portanto, não há o respectivo erro-padrão da média. Em cada categoria de desenvolvimento dos túbulos seminíferos (colunas), valores seguidos de letras idênticas não diferem $(P>0,05)$ significativamente.

* Values between brackets represent the number of bulls castrated at each age. At 14 weeks, samples were collected from only one bull and, therefore, no standard error of the mean is shown. For each category of seminiferous tubule development (within columns), values followed by identical letters are not statistically significant ( $P>0.05)$. 
Tabela 2 - População de células Sertoli e germinativas por secções transversais de túbulos seminíferos em touros Angus em diferentes idades

Table 2 - Sertoli and germ cell populations in cross sections of seminiferous tubules of Angus bulls at different ages

Idade (semanas)
Age (weeks) $\quad \begin{gathered}\text { Células de Sertoli e germinativas por } \\ \text { secções transversais de túbulos seminíferos (média } \pm \text { erro-padrão) } \\ \text { Sertoli and germ cells in cross sections of } \\ \text { seminiferous tubules (mean } \pm \text { standard error) }\end{gathered}$

\begin{tabular}{|c|c|c|c|c|c|}
\hline $10(3)^{*}$ & $35,5 \pm 2,5^{\mathrm{a}}$ & $1,4 \pm 0,1^{\mathrm{a}}$ & 0 & 0 & 0 \\
\hline 14 (1) & 35,1 & 1,6 & 0,6 & 0 & 0 \\
\hline $18(3)$ & $35,2 \pm 2^{\mathrm{a}}$ & $1,6 \pm 0,3^{\mathrm{a}}$ & $1,1 \pm 0,3^{\mathrm{a}}$ & 0 & 0 \\
\hline 22 (3) & $26,5 \pm 1,6^{b}$ & $1,7 \pm 0,3^{\mathrm{a}}$ & $2,5 \pm 0,5^{b}$ & $4,5 \pm 1,8^{\mathrm{a}}$ & 0 \\
\hline $26(3)$ & $28,8 \pm 2,5^{b}$ & $0,8 \pm 0,3^{b}$ & $2,1 \pm 0,3^{b}$ & $7,1 \pm 1,3^{\mathrm{a}}$ & $0,6 \pm 1,2^{\mathrm{a}}$ \\
\hline $30(5)$ & $26,5 \pm 5,9^{b}$ & $0,8 \pm 0,1^{\mathrm{b}}$ & $2,2 \pm 0,5^{b}$ & $13,5 \pm 1,5^{b}$ & $9,1 \pm 4,7^{b}$ \\
\hline 34 (3) & $23,6 \pm 1,5^{b, c}$ & $0,8 \pm 0,3^{b}$ & $3,1 \pm 0,7^{b}$ & $23,6 \pm 6,2^{\mathrm{c}}$ & $20,6 \pm 6,9^{\mathrm{c}}$ \\
\hline 38 (4) & $18,1 \pm 1^{b, c}$ & $0,8 \pm 0,1^{\mathrm{b}}$ & $2,6 \pm 0,4^{b}$ & $24,6 \pm 4,1^{\mathrm{c}}$ & $28,1 \pm 2,6^{\mathrm{d}}$ \\
\hline
\end{tabular}

* Valores entre parênteses representam o número de touros castrados em cada idade. Na $14^{a}$ semana de idade, as amostras foram coletadas de apenas um touro e, portanto, não há o respectivo erro-padrão da média. Em cada categoria de desenvolvimento dos túbulos seminíferos (colunas), valores seguidos de letras idênticas não diferem significativamente $(P>0,05)$.

* Values between brackets represent the number of bulls castrated at each age. At 14 weeks, samples were collected from only one bull and, therefore, no standard error of the mean is shown. For each category of seminiferous tubule development (within columns), values followed by identical letters are not statistically significant ( $P>0.05$ ).

espermática do animal na fase adulta. Estudos realizados com animais Bos taurus adultos têm comprovado que testículos com maior diâmetro e mais pesados possuem número mais elevado de espermátides arredondadas por célula de Sertoli nos túbulos seminíferos (Moura \& Erickson, 1997) e maior produção espermática diária (Berndtson et al., 1987). Em touros Nelore, a relação espermátide/célula de Sertoli também se correlaciona ao peso testicular e à concentração espermática (Carneiro Jr. et al., 2001).

As células de Sertoli apresentaram-se, até a $14^{\mathrm{a}}$ semana de idade, com núcleo e nucléolo arredondado situados majoritariamente próximos à membrana basal do túbulo (Figura 2). Na $18^{\mathrm{a}}$ semana, observaram-se alguns poucos núcleos com formato irregular, porém, sem fendas na membrana nuclear (Figura 3). As reentrâncias na membrana nuclear foram detectadas a partir da $22^{\mathrm{a}}$ semana, quando foi observado um distanciamento de alguns núcleos da lâmina basal do túbulo seminífero (Figura 4). O nucléolo, por sua vez, apresentou-se com estrutura também mais irregular, podendo ser única, bi ou tripartida, conforme descrito por Sinowatz \& Amselgruber (1990) e Wrobel (2000). Estes aspectos do nucléolo e do núcleo das células de Sertoli observados às 18 e 22 semanas coincidiram com a ocupação dos túbulos seminíferos por espermatócitos (22 semanas) e antecederam sua diferenciação em espermátides arredondadas (26 a 30 semanas), alongadas ou maduras (34 semanas). A partir da $26^{\mathrm{a}}$ semana (Figura 5), as células de Sertoli apresentaram-se com o núcleo notavelmente mais irregular e, após 34 ${ }^{\mathrm{a}}$ semana (Figura 6), os núcleos e nucléolos tornaram-se pálidos e com formato mais indefinido. Estes resultados evidenciam a sincronização entre algumas alterações morfológicas das células de Sertoli e o desenvolvimento da espermatogênese (Sinowatz \& Amselgruber, 1990) e, conseqüentemente, das gônadas. As mudanças na morfologia das células de suporte são importantes (Figuras 2 a 6), pois estudos têm comprovado que estão associadas a mecanismos de diferenciação (Wrobel, 2000). Alterações nestes mecanismos têm consequência sobre a idade à puberdade (Sharpe et al., 2003) e, por outro lado, interrupções no curso normal da mitose ou meiose das células germinativas interferem nas mudanças morfológicas e na diferenciação das céluas de Sertoli (Moura \& Erickson, 2001).

As concentrações plasmáticas de FSH reduziram entre a $10^{\mathrm{a}}$ e a $14^{\mathrm{a}}$ semanas de idade nos touros Angus e, a partir de então, elevaram-se até a $22^{\mathrm{a}}$ semana, quando voltaram a decrescer (Figura 7). Os níveis de LH na circulação periférica apresentaram crescimento gradual, mas consistente, da $10^{\text {a }}$ a $30^{\mathrm{a}}$ semanas, estabilizando-se a partir de então (Figura 7). Estes padrões de secreção de FSH e LH são similares aos observados anteriormente em touros (MacDonald et al., 1991; Chandolia et al., 1997; Moura \& Erickson, 1997). Embora o FSH tenha reconhecidamente efeito estimulador sobre a mitose das células de Sertoli (Buzzard et al., 2002; Sharpe et al., 2003), este hormônio também contribui com o processo de diferenciação (Dorrington et al., 1979; Walker \& Cheng, 2005) e a síntese de fatores de crescimento pelas células de Sertoli, os quais promovem a maturação das células de Leydig (Sharpe, 1994; Walker \& Cheng, 2005), tornando-as aptas a responder aos 


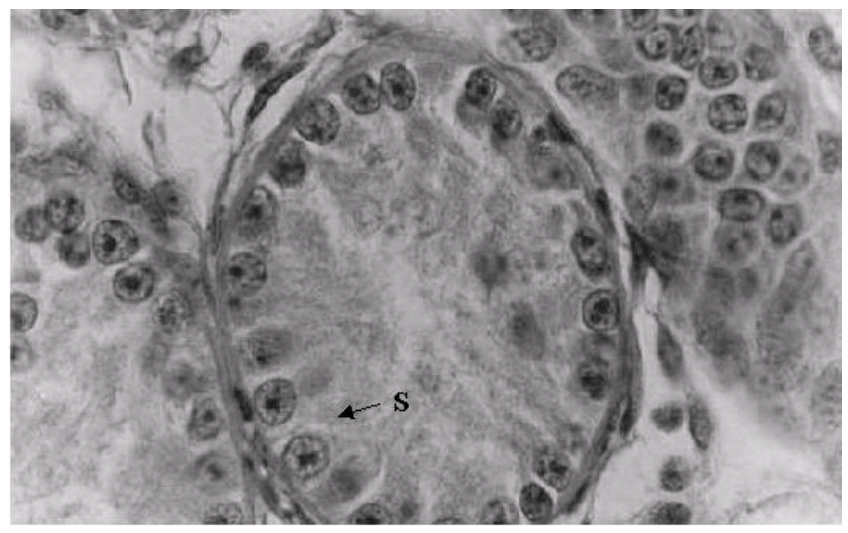

Figura 2 - Túbulos seminíferos de touros Angus de 14 semanas de idade, em seção transversal $(1.000 \mathrm{x})$. S: células de Sertoli.

Figure 2 - Seminiferous tubules of Angus bulls at 14 weeks of age, in transversal section $(1,000 x)$. S: Sertoli cells.

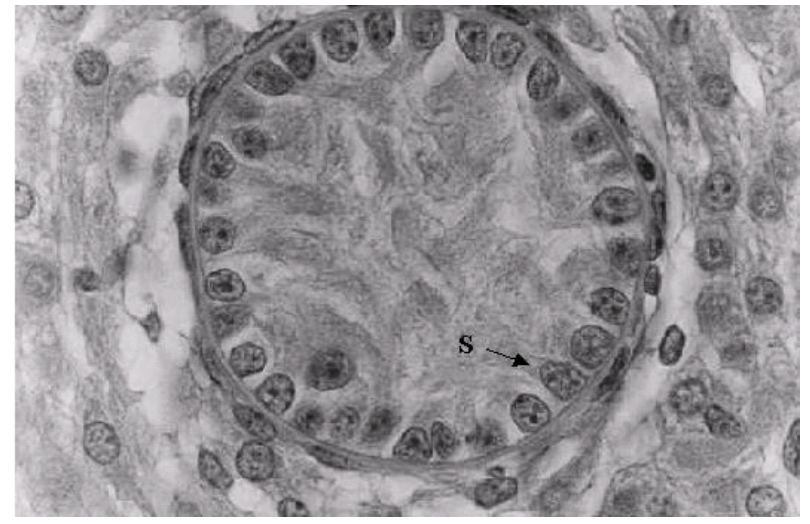

Figura 3 - Túbulos seminíferos de touros Angus de 18 semanas de idade, em seção transversal $(1.000 \mathrm{x})$. S: células de Sertoli.

Figure 3 - Seminiferous tubules of Angus bulls at 18 weeks of age, in transversal section $(1,000 \mathrm{x})$. S: Sertoli cells.

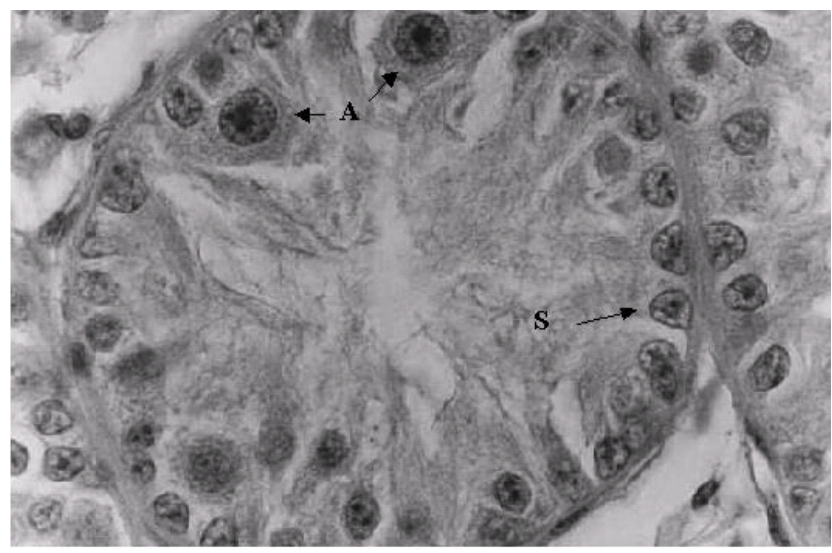

Figura 4 - Túbulos seminíferos de touros Angus de 22 semanas de idade, em seção transversal $(1.000 \mathrm{x})$. S: células de Sertoli; A: espermatogônia A.

Figure 4 - Seminiferous tubules of Angus bulls at 22 weeks of age, in transversal section $(1,000 \mathrm{x})$. S: Sertoli cells; $A$ : $A$ spermatogonia.

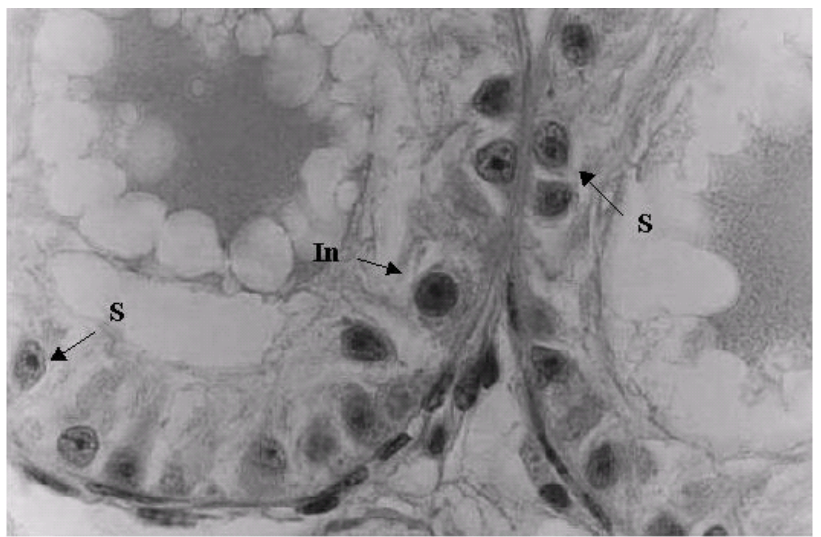

Figura 5 - Túbulos seminíferos de touros Angus de 26 semanas de idade, em seção transversal $(1.000 \mathrm{x})$. S: células de Sertoli; In: espermatogônia intermediária.

Figure 5 - Seminiferous tubules of Angus bulls at 26 weeks of age, in transversal section $(1,000 \mathrm{x})$. S: Sertoli cells; In: intermediate spermatogonia.

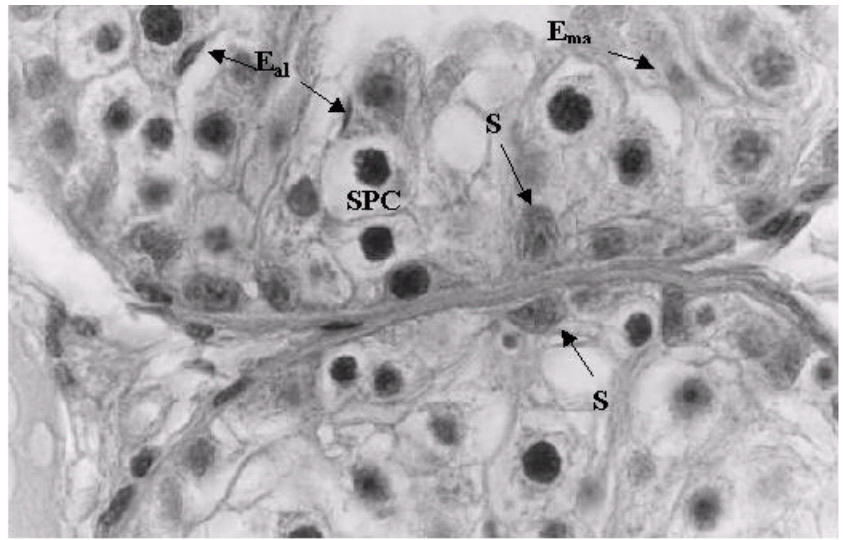

Figura 6 - Túbulos seminíferos de touros Angus de 34 semanas de idade, em seção transversal (1.000 x). S: células de Sertoli; SPC: espermatócito; $\mathrm{E}_{\mathrm{al}}$ : espermátide alongada; $\mathrm{E}_{\mathrm{ma}}$ : espermátide madura.

Figure 6 - Seminiferous tubules of Angus bulls at 34 weeks of age, in transversal section $(1,000 x)$. S: Sertoli cells; SPC: spermatocytes; $E_{a l}$ : elongate spermatid; $E_{m a}$ : mature spermatid.

estímulos crescentes do LH e sintetizar prioritariamente testosterona. Neste estudo, os aumentos mais significativos dos níveis plasmáticos de testosterona (Figura 8) coincidiram com as mudanças morfológicas detectadas no nucléolo e núcleo das células de Sertoli a apartir das 26 semanas (Figuras 4 a 6). Esta associação cronológica está de acordo com a concepção de que a atividade das células de Leydig também influencia a maturação das células de Sertoli, via secreção de testosterona. De fato, Arslan et al. (1993) mostraram a ocorrência de significativo aumento no citoplasma e modificações nas características morfológicas do núcleo das células de Sertoli em macacos (Macaca mullata) tratados exclusivamente com testosterona e, mais recentemente, Buzzard et al. (2003) reportaram que o trata- 

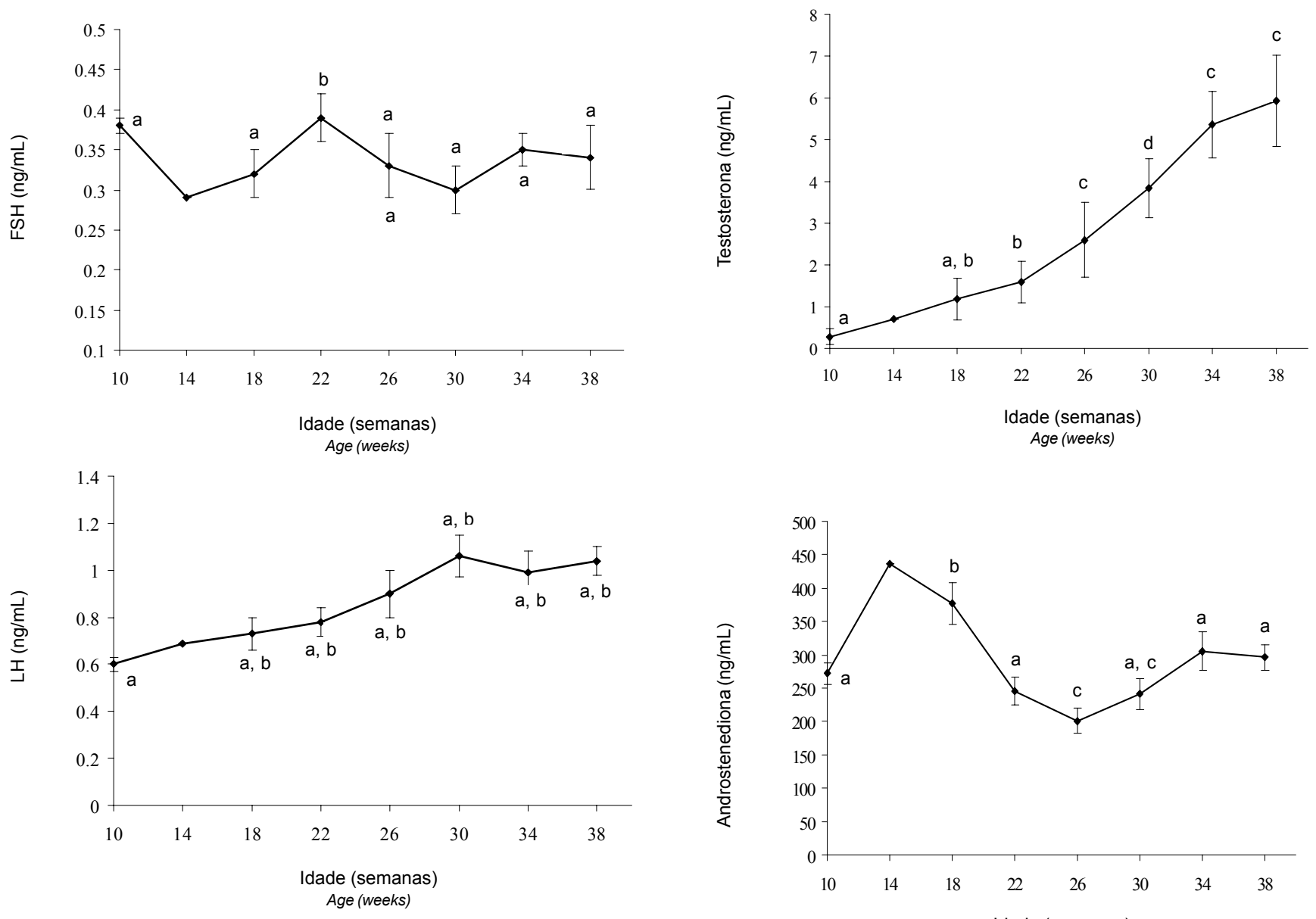

Figura 7 - Concentrações plasmáticas de FSH e LH em touros Angus (médias \pm desvio-padrão). Valores seguidos de letras idênticas não diferem significativamente $(P>0,05)$. Na $14^{a}$ semana, as amostras foram coletadas de apenas um touro e, portanto, não há o respectivo erro-padrão da média.

Figure 7 - FSH and LH plasma concentrations in Angus bulls (mean \pm standard error). Values followed by identical letters are not statistically significant $(P>0.05)$. At 14 weeks, samples were collected from only one bull and, therefore, no standard error of the mean is shown.

mento de células de Sertoli com testosterona (in vitro) induz a expressão de genes associados ao processo de diferenciação dessas células. Por outro lado, seres humanos com mutações nos receptores de andrógenos possuem atividade mitótica prolongada e diferenciação anormal das células de Sertoli (Fuqua et al., 1996).

Enquanto as concentrações periféricas de testosterona apresentaram reduzida variação até as 22 semanas de idade nos touros Angus, mas com aumentos significativos a partir desta idade, a secreção de androstenediona teve um padrão coincidentemente inverso (Figura 8). Esta transição no tipo de andrógeno predominante sintetizado pelos testículos é um indicativo da diferenciação das células de Leydig e de importantes atributos das gônadas na pós-
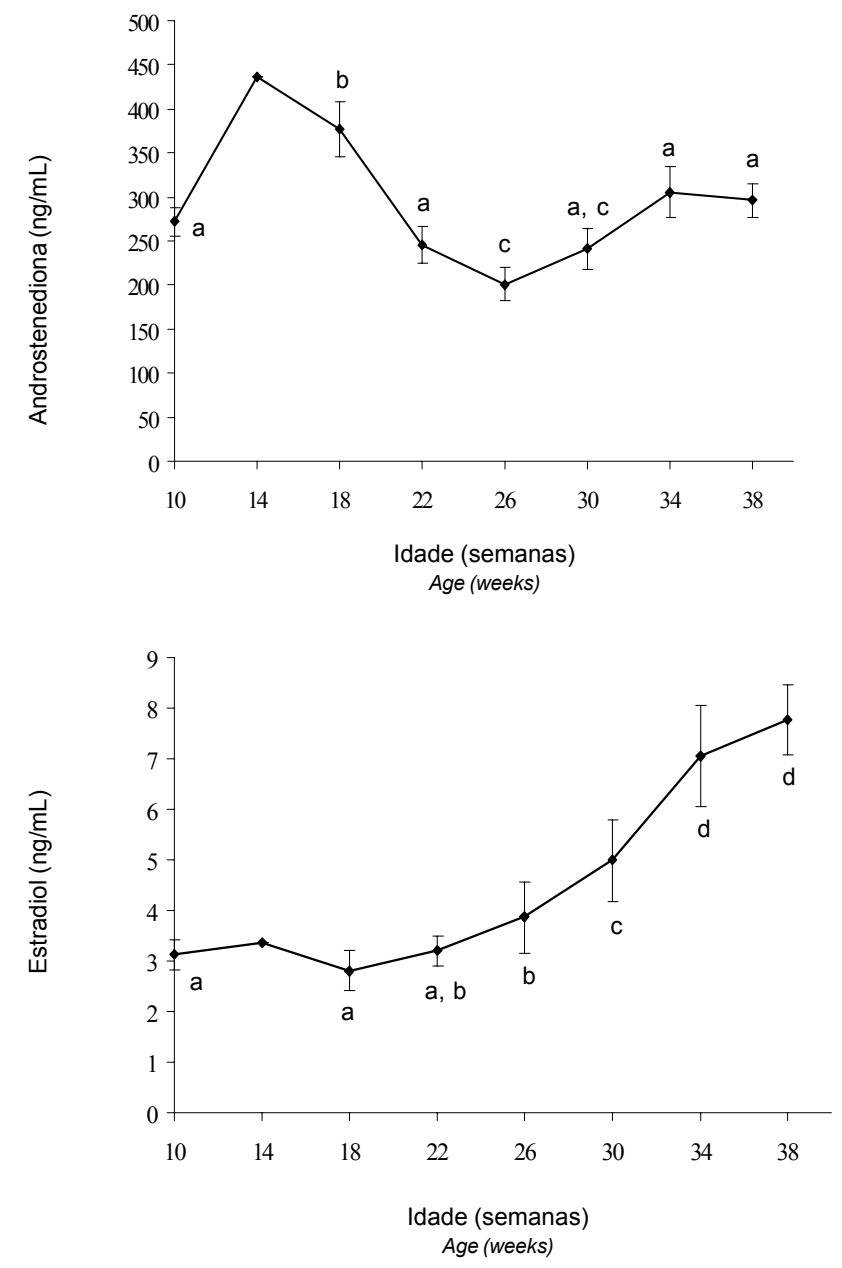

Figura 8 - Concentrações plasmáticas de testosterona, androstenediona e estradiol $17 \beta$ em touros Angus (médias \pm desvio-padrão). Valores seguidos de letras idênticas não diferem significativamente $(P>0,05)$. Na $14^{\mathrm{a}}$ semana, as amostras foram coletadas de apenas um touro e, portanto, não há o respectivo erro-padrão da média.

Figure 8 - Plasma concentrations fortestosterone, androstenedione and estradiol $17 \beta$ in Angus bulls (mean \pm standard error). Values followed by identical letters are not statistically significant $(P>0.05)$. At 14 weeks, samples were collected from only one bull and, therefore, no standard error of the mean is shown. 
puberdade (Bedair \& Thibier, 1979; Curtis \& Amann, 1981; Moura \& Erickson, 1997). Estudos publicados por Moura \& Erickson (1997) demonstraram que os touros que atingem este período de transição mais precocemente têm testículos maiores e produzem mais células germinativas em idades posteriores do desenvolvimento reprodutivo.

As concentrações plasmáticas de estradiol permaneceram sem alterações significativas até a $22^{\mathrm{a}}$ semana de idade, período a partir do qual elevaram continuamente (Figura 8), resultado semelhante ao descrito anteriormente por Amann et al. (1986), Evans et al. (1996) e Moura \& Erickson (1997). A síntese de estradiol no início do desenvolvimento das gônadas pode ser resultado da ação do FSH sobre as células de Sertoli não diferenciadas (ainda na fase prépúbere) e, após esta fase, seria produzido, unicamente ou em conjunto, pelas células de Leydig em processo de diferenciação e sob o estímulo do LH (Dorrington \& Armstrong, 1979; Dorrington \& Khan, 1993; Moura \& Erickson, 1997). As céluas germinativas também sintetizam estradiol nos túbulos seminíferos, ductos eferentes e epidídimo (Hess et al., 1997; Hess \& Bahr, 2001). Todavia, não se conhece qual a contribuição exata desta atividade secretora para os níveis de estradiol detectados na circulação periférica. Nos ductos eferentes e no epidídimo, o estradiol produzido pelas células germinativas atua de forma localizada e uma de suas funções é regular a absorção dos fluidos provenientes dos túbulos seminíferos (Hess \& Bahr, 2001).

É importante notar que, neste estudo com os touros Angus, o incremento significativo nas concentrações periféricas de testosterona e estradiol ocorreu em fases praticamente idênticas (a partir das 26 semanas) e coincidiu com as modificações morfológicas do nucléolo e núcleo, associadas à diferenciação das células de Sertoli (Figuras 4 a 6), com predominância de células meióticas no lúmen dos túbulos seminíferos e crescimento do peso e do diâmetro das gônadas. Estudos têm mostrado claramente que a testosterona está relacionada ao desenvolvimento das gônadas (Curtis \& Amann, 1981; Moura \& Erickson, 1997), exercendo papel fundamental na manutenção da espermatogênese (Zirkin et al., 1994) e transcrição de genes que controlam a atividade mitótica e a diferenciação das células de Sertoli (Buzzard et al., 2003). Entretanto, as associações cronológicas entre a evolução do epitélio seminífero e os níveis de estradiol na circulação periférica apresentadas neste artigo não haviam sido observadas em bovinos. No entanto, os efeitos da ação do estradiol sobre a espermatogênese ainda não foram detalhadamente estudados como a testosterona. De acordo com Pentikainem et al. (2000), o estradiol tem a capacidade de evitar a apoptose de espermatócitos primários e espermátides em seres humanos e é possível que este esteróide contribua de forma significativa para o processo de espermatogênese assim como a testosterona.

\section{Conclusões}

Os resultados evidenciam a existência de uma relação cronológica entre os níveis periféricos de gonadotrofinas e esteróides, a espermatogênese e o desenvolvimento testicular nos touros Angus. No entanto, as variações nos níveis basais de testosterona e estradiol $17 \beta$ e a medida de peso testicular provavelmente são os melhores indicadores da evolução do processo espermatogênico nos túbulos seminíferos. O estudo dos estádios iniciais do desenvolvimento testicular dos touros é fundamental para a compreensão dos fatores que potencialmente influenciam a futura capacidade de produção espermática.

\section{Agradecimento}

À Fundação Cearense de Apoio ao Desenvolvimento Científico e Tecnológico (FUNCAP), pelo financiamento da bolsa para o programa de mestrado da primeira autora, Gyselle Viana Aguiar.

\section{Literatura Citada}

AMANN, R.P. Sperm production rates. In: JOHNSON, A.D.; GOMES W.R.; VANDEMARK, N.L. (Eds.) The testis. New York and London: Academic Press, 1970. v.1, p.433-482.

ANWAY, M.D.; LI, Y.; RAVINDRANATH, N. et al. Expression of testicular germ cell genes identified by differential display analysis. Journal of Andrology, v.24, n.2, p.173-184, 2003.

ARSLAN, M.; WEINBAUER, G.F.; SCHLATT, S. et al. FSH and testosterone, alone or in combination, initiate testicular growth and increase the number of spermatogonia and Sertoli cells in a juvenile non-human primate (Macaca mullata). Journal of Endrocrinology, v.136, p.235-243, 1993.

ARVINDAKSHAN, J.P.; HONARAMOOZ, A.; BARTLEWSKI, P.M. et al. Pattern of gonadotropin secretion and ultrasonographic evaluation of developmental changes in the testis of early and late maturing bull calves. Theriogenology, v.54, p.339-354, 2000.

BEDAIR, G.A.M.; THIBER, M. Peripheral plasma androstenedione and testosterone concentrations in bulls before and during puberty. Journal of Reproduction and Fertility, v.56, p. 7-10, 1979 .

BERNDTSON, W.E.; IGBOELI G.; PARKERM, W.G. The numbers of Sertoli cells in mature Holstein bulls and their relationship to quantitative aspects of spermatogenesis. Biology of Reproduction, v.37, n.1, p.60-67, 1987.

BOLT, D.J. Development of homologous radioimmunoassay for ovine follicle stimulating hormone: studies of estrous, ovariectomy, estradiol and releasing hormone. Journal of Animal Science, v.53, p.730-738, 1981.

BOLT, D.J.; ROLLINS, R. Development and application of a radioimmunoassay for bovine follicle stimulating hormone. Journal of Animal Science, v.56, p.146-153, 1983. 
BOOCKFOR, F.R.; BARNES, M.A.; DICKEY, J.F. Effects of unilateral castration and unilateral cryptorchidism of the Holstein bull on in vitro Leydig cell response. Journal of Animal Science, v.56, p.1386-1392, 1983.

BUZZARD, J.J.; WREFORD, N.J.; MORRISON, J.R. Marked extension of proliferation of rat Sertoli cells in culture using recombinant human FSH. Reproduction, v.124, p.633-641, 2002.

BUZZARD, J.J.; WREFORD, N.G.; MORRISON, J.R. Thyroid hormone, retinoic acid, and testosterone suppress proliferation and induce markers of differentiation in cultured rat Sertoli cells. Endocrinology, v.144, n.9, p.3722-3731, 2003.

CARNEIRO JR., J.H.; RODRIGUES, G.; MOURA, A. Testicular development, peripheral concentrations of testosterone and histology of the seminiferous tubules in Nelore bulls. In: CONGRESSO DE INTEGRAÇÃO EM BIOLOGIA DA REPRODUÇÃO, 2., 2001, Ribeirão Preto. Anais... Ribeirão Preto: 2001. p.46.

CASTRO, A.C.S.; BERNDTSON, W.E.; CARDOSO, F.M. Cinética e quantificação da espermatogênese: bases morfológicas e sua aplicação em estudos da reprodução de mamíferos. Revista Brasileira de Reprodução Animal, v.21, n.1, p.25-34, 1997.

CHANDOLIA, R.K.; HONARAMOOZ, A.; OMEKE, B.C. et al. Assessment of development of the testes and accessory glands by ultrasonographic in bull calve and associated endocrine changes. Theriogenology, v.48, p.119-132, 1997.

COUROT, M.; HOCHEREAU-de RIVIERS, M.T.; ORTAVANT, R. Spermatogenesis. In: JOHNSON, A.D.; GOMES W.R,; VANDEMARK, N.L. (Eds.) The testis. New York and London: Academic Press, 1970. v.1, p.339-432.

COX, N.M.; RAMIREZ, J.L.; MATAMOROS, I.A. et al. Influence of season on estrous and luteinizing hormone responses to estradiol benzoate in ovarioectomized sows. Theriogenology, v.27, p.395-404, 1987

CURTIS, S.K.; AMANN, R.P. Testicular development and establishment of spermatogenesis in Holstein bulls. Journal of Animal Science, v.53, n.6, p.1645-1657, 1981.

DORRINGTON, J.H.; KHAN, A. Steroid production, metabolism, and release by Sertoli cell. In: RUSSELL, L.D.; GRISWOLD, M.D. (Eds.) The Sertoli cell. Clearwater: Cache Rever Press, 1993. p.538-547.

DORRINGTON, J.H.; AMSTRONG, D.T. Effects of FSH on gonadal function. Recent Progress in Hormone Research, v.35, p.301, 1979.

EVANS A.C.O.; PIERSON, R.A.; GARCIA, A. et al. Changes in circulating hormone concentrations, testes histology and testes ultrasonography during sexual maturation in beef bulls. Theriogenology, v.46, p.345-357, 1996.

FUQUA, J.S.; SHER, E.S.; PERLMAN, E.J. et al. Abnormal gonadal differentiation in two subjects with ambiguous genitalia, Mullerian structures, and normally developed testes: evidence for a defect in gonadal ridge development. Human Genetics, v.97, p.506-511, 1996

GRIFFIN, J.E. Male reproductive funtion. In: GRIFFIN, J.E.; OJEDA, S.R (Eds.). Textbook of endocrine physiology. New York: Oxford University Press, 1988. p.165-185.

HESS, R.A.; BUNICK, D.; BAHR, J. Oestrogen, its receptors and function in the male reproductive tract - a review. Mollecular Cellular Endocrinology, v. 178, n.1-2, p.29-38, 2001.

HESS, R.A.; BUNICK, D.; LEE, K.H. et al. A role for oestrogens in the male reproductive system. Nature, v.390, n.6659, p.509-512, 1997.

MacDONALD, R.D.; DEAVER, D.R.; SCHANBACHER, B.D. Prepubertal changes in plasma FSH and inhibin in Holstein bull calves: responses to castration and(or) estradiol. Journal of Animal Science, v.69, p.276-282, 1991.

MACKAY, S. Gonadal development in mammals at the cellular and molecular levels. International Review of Cytology - A Survey of Cell Biology, v.200, p.47-99, 2000.
MARTIN-du PAN, R.C.; CAMPANA, A. Physiopathology of spermatogenic arrest. Fertility and Sterility, v.60, n.6, p.937-946, 1993.

MOURA, A.A.; ERICKSON, B.H. Age-related changes in peripheral hormone concentrations and their relationships with testis size and number of Sertoli and germ cell in yearling beef bulls. Journal of Reproduction and Fertility, v.111, p.183-190, 1997.

MOURA, A.; ERICKSON, B.H. Níveis hormonais durante a prépuberdade como indicadores do desenvolvimento testicular em touros Angus. In: REUNIÃO ANUAL DA SOCIEDADE BRASILEIRA DE ZOOTECNIA, 34., 1997, Juiz de Fora. Anais... Juiz de Fora: Sociedade Brasileira de Zootecnia, 1997. p. $432-434$.

MOURA, A.A.; ERICKSON, B.H. Respostas hormonais ao tratamento com GnRH e estradiol e suas correlações com desenvolvimento testicular e número de células Sertoli em touros Angus x Charolês na fase de pré-puberdade. Revista Brasileira de Zootecnia, v.28, n.2, p.30-39, 1999.

MOURA, A.A.; ERICKSON, B.H. Testicular development, histology, and hormone profiles in three yearling Angus bulls with spermatogenic arrest. Theriogenology, v.55, p.1469$1488,2001$.

NISWENDER, G.D.; RICHERT, JR., L.E.; MIDGLEY JR., H. et al. Radioimmunoassay for bovine and ovine luteinizing hormone. Endocrinology, v.84, p.1166-1177, 1969.

PENTIKAINEN, V.; ERKKILA, K.; SUOMALAINEN, L. et al. Estradiol acts at a germ cell survival factor in the humam testis in vitro. Journal Clinic Endocrinol Metabolism, v.85, p.2057-2067, 2000.

RUSSEL, L.D.; FRANÇA, L.R. Building a testis. Tissue \& Cell, v.27, n.2, p.129-146, 1995.

STATISTICAL ANALYSIS SYSTEM - SAS. SAS/STAT ${ }^{\circledR}$ User's guide. Version 6, 4.ed. Cary: 2003. v.2.

SHARPE, R.M. Regulation of espermatogenesis. In: KNOBIL, E.; NEILL, J.D. (Eds.). The phisiology of reproduction. 2.ed. New York: Raven Press, 1994. v.1, p.1364-1434.

SHARPE, R.M.; McKINNELL, C.; KIVLIN, C. et al. Proliferation and functinal maturation of Sertoli cells and their relevance to disorders of testis function in adulthood. Reproduction, v.125, n.6, p.769-784, 2003.

SINOWATZ, F.; AMSELGRUBER, W. Postnatal development of bovine Sertoli cells. Anatomy and Embriology, v.174, p.413423, 1986.

SOUZA, C.A. Avaliação da função reprodutivas de carneiros Santa Inês durante o primeiro ano de vida: desenvolvimento testicular, produção espermática e proteínas do plasma seminal. Fortaleza: Universidade Federal do Ceará, 2003. Dissertação (Mestrado em Zootecnia) Departamento de Zootecnia, 2003.

SOUZA, C.A.; MOURA, A.; ARAUJO, A. et al. Testicular development and quantitative aspects of spermatogenesis in rams. In: CONGRESSO DE INTEGRAÇÃO EM BIOLOGIA DA REPRODUÇÃO, 3., 2003, Ribeirão Preto. Anais... Ribeirão Preto: 2003. p.41.

WALKER, W.H. Molecular mechanisms controlling Sertoli cell proliferation and differentiation. Endocrinology, v.144, n.9, p.3719-3721, 2003.

WALKER, W.H.; CHENG, J. FSH and testosterone signalling in Sertoli cells. Reproduction, v.130, p.15-28, 2005.

WROBEL, K-H. Prespermatogenesis and spermatogenesis in the bovine testis. Anatomy and Embryology, v.202, p.209222,2000

ZIRKIN, B.R.; AWONIYI, C.; GRISWOLD, M.D. et al. Is FSH requerid for adult spermatogenesis? Journal of Andrology, v. 15, n.4, p.273-276, 1994

Recebido: $24 / 10 / 03$ Aprovado: 10/04/06 